\title{
1971 ELECTION RESULTS
}

The tellers for the 1971 election, Doris W. Schattschneider and Ruth M. Hailperin, have reported the election of the following members of the council and Board of Trustees. The terms in each case begin on January 1, 1972.

President-Elect, Saunders Mac Lane

Vice-Presidents, Richard D. Anderson, R. Creighton Buck

Associate Secretaries, Paul T. Bateman, Kenneth A. Ross

Member of the Bulletin Editorial Committee, Hans F. Weinberger

Members of the Proceedings Editorial Committee, Glen E. Bredon, W. Wistar Comfort, Lee A. Rubel

Member of the Colloquium Editorial Committee, S. S. Chern

Member of the Mathematical Reviews Editorial Committee, Frederick W. Gehring

Member of the Mathematical Surveys Editorial Committee, Robert G. Bartle

Member of the Transactions and Memoirs Editorial Committee, Alistair H. Lachlan, François Treves

Members-at-large of the Council, William Browder, P. S. Mostert, Dorothy Maharam Stone, Olga Taussky Todd

Member of the Board of Trustees, Richard S. Palais

EVERETT Pitcher, Secretary 